\section{Estar y producir en colectivo. Reflexiones sobre los saberes desde la experiencia de los Espacios de Formación Integral de la Universidad de la República}

Valeria Cavalli Dalla Rizza

Universidad de la República, Uruguay.

vcavalli@psico.edu.uy

(iD) orcid.org/0000-0002-9006-2242
Sujetos y relaciones en extensión universitaria /
RECEPCIÓN: 26/06/20

ACEPTACIÓN FINAL: 21/08/20

\section{Resumen}

En el presente artículo compartimos algunas reflexiones epistemológicas y teóricas en torno a la integralidad como perspectiva que requiere una transformación en la concepción de la ciencia y la enseñanza universitaria y que apuesta a coproducir conocimiento desde el diálogo de saberes. Nos centramos en la experiencia de los Espacios de Formación Integral de la Universidad de la República como dispositivos pedagógicos que favorecen la relación entre los sujetos y sus saberes y disponen a producir colectivamente desde el estar y ser juntos y juntas. Asimismo, introducimos algunos abordajes metodológicos y estrategias didácticas que promueven la participación y la coproducción. Finalmente, problematizamos sobre la propia noción de diálogo de saberes, pensándolo como meta y guía de la integralidad, y planteamos que los Espacios de Formación Integral permiten producir prácticas educativas a partir del diálogo entre actores y actoras involucrados.

Palabras clave: diálogo de saberes; formación integral; coproducción de conocimiento; extensión universitaria.
Being and producing collectively. Reflections about knowledge from the experience of the Integral Training Spaces

\section{Abstract}

In this article we share some epistemological and theoretical reflections on integrality as a perspective that requires a transformation in the conception of science and university teaching, which aims to co-produce knowledge from the dialogue of knowledge. We focus on the experience of the Integral Training Spaces of the University of the Republic, as pedagogical devices that favor the relationship between the subjects and their knowledge, as well as preparing to collectively produce from being together. Likewise, we introduce some methodological approaches and didactic strategies that promote participation and co-production. Finally, we problematize the notion of dialogue of knowledge, thinking of it as a goal and guide to integrality, and we suggest that the Integral Training Spaces allow the production of educational practices based on dialogue between involved actors.

Keywords: dialogue of knowledge; integral training; co-production of knowledge; University Extension.
Estar e produzir coletivamente. Reflexões sobre os saberes a partir da experiência dos Espaços de Formação Integral

\section{Resumo}

Neste artigo, compartilhamos algumas reflexões epistemológicas e teóricas sobre a integralidade como uma perspectiva que requer uma transformação na concepção da ciência e do ensino universitário, que aposta a coproduzir o conhecimento a partir do diálogo de saberes. Fazemos foco na experiência dos Espaços de Formação Integral da Universidade da República como dispositivos pedagógicos que favorecem a relação entre os sujeitos e seus conhecimentos e as disposições para a sua construção colectiva. Assim, introduzem-se abordagens metodológicas e estratégias didácticas que incentivam a participação e a coprodução. Por último, problematiza-se a propria noção de diálogo de saberes, pensando-o como uma meta e guia da integralidade e propomos os Espaços de Formação Integral como práticas educacionais baseadas no diálogo entre atores envolvidos.

Palavras-chave: diálogo de saberes; formação integral; coprodução de conhecimento; extensão universitária. 


\title{
Introducción
}

Los pensamientos aquí presentados surgen de mi experiencia como universitaria extensionista, la que se articula con actividades de enseñanza, investigación y gestión desde una perspectiva integral. Las preguntas y preocupaciones en torno al trabajo con otros y otras que esbocé en los inicios de mi formación universitaria aún hoy están vigentes. Sin embargo he logrado, desde mi experiencia vivida y en colectivo siempre, delimitarlas como problemas de estudio e intervención y profundizar teóricamente en ellas. Las reflexiones a las que arribo en este texto surgen fundamentalmente a partir de la realización de mi tesis de Maestría en Psicología y Educación "Imágenes de un aula en movimiento. Pensamientos sobre los saberes en la enseñanza universitaria integral" (Cavalli, 2019) y se afianzan en prácticas y actividades desarrolladas posteriormente, sobre todo en el marco de mi tarea docente.

Nos centramos en las prácticas integrales orientadas por actividades de extensión, particularmente en los Espacios de Formación Integral (EFI). Los mismos fueron creados en 2008 por la Universidad de la República (UdelaR) para integrar la extensión a la formación curricular de estudiantes. Se trata de espacios pedagógicos en los que se llevan adelante las funciones universitarias de investigación, enseñanza y extensión de manera articulada, desde un abordaje interdisciplinario y con diálogo de saberes. Para el desarrollo de los mismos, en primer lugar identificamos la necesidad de un posicionamiento epistemológico que implica una transformación en la manera de pensar la universidad, la producción de conocimiento y la enseñanza universitaria. Un posicionamiento desde una mirada compleja para entender los problemas que requiere abordajes desde el diálogo y la coproducción. Por otro lado, se nos impone como una necesidad ineludible pensar en torno al saber, a los modos de producirlo, transmitirlo y generarlo. Con posterioridad encontramos en el dispositivo EFI la capacidad de habitar el tiempo y el espacio y de producir nuevos pensamientos. Luego identificamos algunos abordajes y estrategias metodológicas y didácticas que favorecen el encuentro, que promueven el diálogo entre actores y actoras que participan en prácticas de extensión e integrales y que, de esta manera, logran generar saberes y conocimientos producidos colectivamente. Para finalizar, identificamos la necesidad de repensar el diálogo de saberes a partir de la experiencia de los EFI y entenderlo como meta y guía de las prácticas integrales.

\section{Otros modos para producir en colectivo}

\author{
"Pero, por eso mismo, debemos \\ interpelar a todos aquellos que \\ ocupan una posición docente \\ en las ciencias sociales y \\ psicológicas, o en el campo del \\ trabajo social, todos aquellos \\ cuya profesión consiste en \\ interesarse por el discurso
}

1) Esta tesis fue realizada a partir de la participación como investigadora en el EFI "Relaciones sociedad-naturaleza en la frontera. Personas, animales, pensamiento científico y desarrollo socioeconómico en Paso Centurión, Cerro Largo" en su edición 2017. 
del otro. Se encuentran en una encrucijada política y micropolítica fundamental. $O$ hacen el juego a esa reproducción de modelos que no nos permiten crear salidas a los procesos de singularización o, por el contrario, trabajan para el funcionamiento de esos procesos en la medida de sus posibilidades y de los agenciamientos que consigan poner a funcionar". (Guattari \& Rolnik, 2006, p. 43)

Situarnos en la perspectiva de la extensión en clave de integralidad nos lleva a pensar en procesos de aprendizaje y de construcción de conocimiento que reconozcan e integren el saber de actores y actoras no universitarios. Supone entender los procesos pedagógicos favorecidos por modelos centrados en la formación (Cano \& Castro, 2013; Kachinovsky \& Gatti, 2005), en donde los sujetos de la educación van juntos hacia la construcción del saber. Esto nos coloca frente al problema - o posibilidad- de pensar en propuestas con diálogo de saberes. Desde la extensión y la integralidad, se ha tomado la perspectiva de la "ecología de saberes" (Sousa Santos, 2006, 2010) para entender el diálogo de saberes en las prácticas integrales. Esta noción nos permite pensar en otro modo de comprender la enseñanza universitaria y la producción de conocimiento científica, así como de considerar los saberes y los modos en que estos se relacionan, aprenden, enseñan, transmiten y construyen. Asimismo, supone reivindicar otros saberes desde "la relación que se establece (...) entre sujetos que contribuyen con su conocimiento a la producción de un nuevo saber desde el diálogo" (CSEAM, 2015, p. 17). En este sentido, decimos que el diálogo de saberes implica una disposición (en tanto posición) horizontal y bidireccional que permite la construcción colectiva entre saberes diversos y sobre todo se trata de una experiencia colectiva de creación.

Sin embargo, plantear una propuesta con diálogo de saberes nos enfrenta, además, al desafío de proponernos otras maneras de pensar la ciencia, la enseñanza y el aprendizaje. Supone preguntarnos cómo pensamos, si es posible pensar de otra forma (Foucault, 2011) y cómo hacer para estar juntos y juntas (Skliar, s.f.) en la universidad.

Epistemológicamente, se entiende a las problemáticas sociales desde una perspectiva compleja, que requiere un abordaje con múltiples miradas, integrando disciplinas, actores y actoras, articulando funciones universitarias con el fin de transformar una situación. Nos posicionamos desde la incomodidad que los problemas que abordamos nos generan. Nos resultan incómodos, nos molestan, nos interpelan. De esta manera, como plantea Ana María Fernández (2007), la incomodidad se transforma en un método de trabajo. Pero también estos problemas nos mantienen inconformes. Necesitamos hacer algo. Esto significa, desde una perspectiva crítica de lo establecido, pensar por qué las cosas son de determinada manera y no de otra (Percia, 2010), cómo podemos hacer para que sean distintas. Atendiendo a nuestra incomodidad e inconformidad encontramos una (otra) posibilidad de hacer, de pensar, de producir, de investigar. Se trata de un modo de estar, pensar y producir 
desde una epistemología del encuentro, cercana, una epistemología pasional, como expresa Larrosa (2009). Una producción desde el deseo (Guattari \& Rolnik, 2006).

El deseo se transforma en motor de producciones. Se trata del deseo "como modo de vivir, de crear, de amar (...), de inventar otra sociedad (p. 225). Como modo de entender y comprender la realidad y las relaciones que en la misma se establecen. Pero también nos lleva a preguntarnos por qué hacer esta práctica y cómo llevarla adelante. El deseo se comporta como motor de transformaciones, porque es necesario imaginar y desear otros mundos para que estos sean posibles.

Por eso decimos que en los EFI se apuesta a relaciones desde el afecto, significan un estar y ser deseante. Hay deseo de encontrarse, de escuchar, de compartir. Hay placer en producir algo nuevo a partir de la reflexión de la propia experiencia. Ello requiere crear una alternativa al pensamiento occidental positivista porque este nos incomoda y no nos conforma. Se trata de generar propuestas alternativas desde el encuentro con otros y otras. Lo que requiere pensar, como plantea Guattari, (1996) con una lógica de la intensidad y del movimiento, de la existencia. Requiere romper la totalidad, crear líneas de fuga y desarrollar prácticas micropolíticas y microsociales. De este modo podremos crear otros universos de referencia, otros territorios para existir. Para el autor, se trata de un "movimiento múltiple" de producción de nuevas subjetividades y, a la vez, de creación de dispositivos de análisis. Necesitamos de nuevos dispositivos de análisis y de otros modos de hacer ciencia y producir conocimiento, ya que, coincidiendo con Sousa Santos (2006), la ciencia está en crisis. Una crisis que reduce las relaciones entre las personas y por ello también la posibilidad de crear nuevas subjetividades (Guattari, 1996). En contraposición buscamos prácticas que propicien relaciones, la creación de redes y de nuevas subjetividades colectivas y rebeldes (Sousa Santos, 2006). Creemos en una universidad que aporte a la justicia social y cognitiva, a procesos de emancipación y de libertad.

Consideramos que desde las prácticas integrales tenemos la posibilidad de encontrar esa riqueza, esa realidad que sucede fuera de los claustros universitarios. En otros territorios donde se produce y acontece la vida de las maneras más diversas y en constante movimiento y transformación. Es allí donde tendremos la oportunidad de encontrarnos con otros y otras, de relacionarnos con sus experiencias y saberes, aquellos necesarios para reinventar la ciencia. Apostamos a una ciencia de las emergencias, una "Espistemología del Sur" (Sousa Santos, 2006) capaz de permitir que distintos saberes dialoguen desde una ecología de saberes, que nos permita ensanchar el presente para ver la diversidad de experiencias que en el mismo existen, de reconocer las diferencias borrando jerarquías, de producir conocimiento situado que valore lo diferente y alternativo. Se trata ni más ni menos que de crear nuevos modos de ser y de estar juntos y juntas (Skliar, 2010). Entendemos que la ciencia y el conocimiento conllevan un proceso colectivo de pensar y crear con otros y otras en un convivir; estar y producir a la luz de la experiencia colectiva. Pero, como decíamos, esto requiere un cambio en la forma de pensar la academia, la ciencia, la validez del conocimiento, sus criterios de rigor, los modos de producirlo y comunicarlo, de enseñar y aprender. Es una invitación a reinventar la ciencia pero también a reinventarnos a nosotros y nosotras. De recuperar nuestra imaginación política (Foucault, 2012), ya que la creatividad y la imaginación se vuelven imprescindibles para "reinventar el conocimiento-emancipación" (Sousa Santos, 2006). 


\section{Lo colectivo como espacio de pensamiento y producción de saberes}

Las prácticas docentes universitarias desde la perspectiva de la integralidad suponen el vínculo con colectivos, organizaciones, instituciones, vecinos y vecinas autónomos, entre otros. En las prácticas cotidianas que estos desarrollan se despliegan diferentes saberes, muchos de ellos con los que se propone dialogar en las actividades que llevamos adelante. Pero no solo los saberes son puestos en juego en las prácticas cotidianas, sino también los modos de generarlos, aprenderlos y transmitirlos, así como la forma en que estos circulan y se relacionan con otros saberes. Para pensar en este campo compartimos la perspectiva de Nygren (1999), quien plantea la importancia de estudiar y describir saberes situados que surgen en una realidad multidimensional de la que los y las actores son parte.

Entendemos que el saber es un conjunto de enunciados y visibilidades respecto de algo en una época dada (Deleuze, 2013). Implica poner en acción prácticas discursivas (Charlot, 2000; Foucault, 2013). El saber se define por las posibilidades de utilización y de apropiación ofrecidas por el discurso (Foucault, 2013). O, como plantea Charlot (2000), el saber implica diferentes prácticas discursivas de argumentación, verificación, experimentación, así como voluntad de demostrar, probar y validar, suponiendo una relación con el lenguaje. Como dice este autor, tiene que ver con las estrategias que los sujetos se dan para comprender el mundo, para ponerlo en orden y dominarlo. Por ello decimos que el saber se despliega en las prácticas cotidianas que los sujetos realizan. Continuando con Charlot $(2000,2008)$, no se trata de un saber en estado puro sino de relación, hay relaciones de los sujetos con el saber, el saber es en la relación de los sujetos, entre los sujetos y con el mundo. Nos valemos del saber para usarlo; de alguna manera se trata de una relación científica con el mundo, de experimentación y validación del mundo en una comunidad (Charlot, 2000).

Así, los procesos de enseñanza y aprendizaje, las prácticas de formación como los EFI, deben favorecer una relación con el saber, porque de otra manera se vuelven frágiles (Charlot, 2000). Esto quiere decir que el aprendizaje debe ser significativo, una experiencia significativa, en tanto aquella que forma deja una huella, una señal (Larrosa, 2009). Se trata de una experiencia subjetiva que deja efectos en cómo voy a pensar y a entender el mundo, cómo voy a saber el mundo. Es una experiencia, una relación con el mundo que da identidad, que cobra sentido en la historia de los sujetos, genera expectativas, concepciones del mundo y de la vida (Charlot, 2000).

A este respecto, resulta fundamental el aporte realizado por el equipo Alternativas $\mathrm{Pe}$ dagógicas y Prospectiva Educativa en América Latina (APPEAL), que ha avanzado y abierto un campo de discusión sobre las alternativas pedagógicas y la relación entre la producción de "saberes" y su "productividad". ${ }^{2}$ Se recuperan las complejas articulaciones entre saber y poder a lo largo de la historia en perspectiva latinoamericana, ubicando el problema de la productividad de los saberes para generar alternativas sociales, políticas, económicas, adecuadas a la realidad de los pueblos, sus tradiciones y sus culturas diversas (Puiggrós, 2013). En ese sentido, el equipo plantea que los saberes se integran en redes o mapas cognitivos, muchas veces difusos, que compartimos con otros y otras cuando llevamos

2) La preocupación por los "saberes" del equipo APPEAL Argentina nació en el marco de la crisis económica, política y social del país producto de las políticas neoliberales de las últimas décadas del siglo y se alimentó de las intensas experiencias sociales generadas en oposición, desde una perspectiva histórica. 
adelante actividades productivas, de aprendizajes y creación. De allí el sustrato social que funda y sostiene a los saberes socialmente productivos.

Son redes de relaciones entre una multiplicidad de articulaciones de diferentes sectores que están involucrados en los procesos productivos materiales y simbólicos, componiendo tejido social (2013). Por eso se habla de saberes socialmente productivos (Puiggrós \& Gagliano, 2004), que son sentidos como significativos por los actores y las actoras, resultado de experiencias, en cuanto a que ese nuevo saber juega un papel en el proceso de construcción de identidad. Además, son saberes en relación con los territorios, por lo que, como mencionamos, son saberes situados. Cabe señalar que se piensa en la categoría "saberes socialmente productivos" en lugar de "saberes productivos" porque es "lo social" lo que juega un papel constitutivo en el relato de vida de los sujetos, lo que otorga a esos saberes estatus distintos $\mathrm{y}$, por supuesto, una productividad distinta.

De esta manera, las experiencias colectivas se constituyen como experiencias significativas (singulares y colectivas) para los sujetos en los que se generan saberes socialmente productivos. Como planta Teles (2009), lo colectivo surge de la potencia de la relacionalidad; somos seres en relación, entramados unos y unas con los otros y otras en un juego de afecciones múltiples (p. 47). Lo colectivo compone un dispositivo (Deleuze, 2007; García F., 2011), una red de relaciones. En cada dispositivo podemos encontrar diversos modos de relaciones con el saber, pero también con otros saberes, con otros sujetos y con el mundo. Un modo de dominio y de entendimiento de la realidad que se construye a través de los discursos que los sujetos tienen disponibles para entender el mundo. Estos discursos y visibilidades son a la vez construidos y puestos en práctica en la experiencia colectiva. $Y$ esta constituye a la vez un saber y un modo de saber, un modo de vida y de hacer mundo, que es experiencial, situado, subjetivo. Además, influyen significativamente en la construcción de trama social en tanto saberes socialmente productivos. Pensamos, entonces, en la capacidad que tienen ciertos sujetos colectivos de lograr producir y restituir saberes que posibiliten la reconstrucción y rearticulación de una trama social diferente, permitiendo así crear alternativas viables en nuevas coyunturas históricas y políticas.

Desde esta perspectiva, cuando hablamos de diálogo de saberes en los EFI y con referencia al planteo de "ecología de saberes" de Sousa Santos, aludimos a la posibilidad de establecer un diálogo horizontal entre saberes diversos que vienen de distintas experiencias. Se trata de una apuesta a la co-construcción a partir de esos saberes.

\section{La potencia de los EFI como dispositivos pedagógicos}

Los EFI surgen en el año 2008 como estrategia para curricularizar la extensión y las prácticas integrales en la UdelaR. Tienen el objetivo de generar "ámbitos para la promoción de prácticas integrales en la Universidad, favoreciendo la articulación de enseñanza, extensión e investigación en el proceso formativo de los estudiantes, promoviendo el pensamiento crítico y propositivo, y la autonomía de los sujetos involucrados" (Udelar, 2010, p. 9). Con esta iniciativa se apuesta a procesos de aprendizaje que favorezcan la formación, para lo que se necesita de dispositivos pedagógicos que se centren en el saber. El dispositivo pedagógico debe generar un escenario de encuentro. Es un proceso de formación colectiva, de construcción de pensamiento y saber, ya que "lo colectivo fuerza pensamiento" (Teles, 2009) y el pensamiento implica relación con el saber. 
En tanto dispositivos (Deleuze, 2007; García F., 2011), los EFI comportan espacios, entramados, redes de relación entre sujetos y saberes en constante puesta en juego, transmisión, aprendizaje y producción. Entonces decimos que estos saberes son a la vez productores de subjetividad y producidos desde la subjetividad colectiva en el entramado que el EFI compone. La subjetividad implica una manera de ver y hablar: de saber, por eso decimos que se trata de espacios capaces de mostrar, de hacer ver, de decir, de contar. Por eso producen subjetividad y también saber, modos de relacionarse con el saber y a través de mismo.

Pensamos en la capacidad que tienen estos espacios para mantenerse en constante movimiento, transformación y producción a través del encuentro. Los EFI pueden crearse y recrearse, nunca son el mismo, cambian y, sobre todo, permiten y promueven el diálogo de saberes porque se inscriben en la posibilidad de lo colectivo.

Asimismo, identificamos dos potencialidades particulares de estos dispositivos pedagógicos. Por un lado, la capacidad de habitar el tiempo y el espacio al construir un aula en movimiento, un "aula itinerante" (Cavalli, 2019). Decimos que los EFI tienen la capacidad de transitar e instalarse en diferentes territorios construyendo una territorialidad pedagógica que mantiene sus objetivos, sus contenidos, pero que cambia de escenario, de estrategias, e integrando diferentes actores y actoras en las distintas escenas. Entendemos al aula como aquel espacio-tiempo donde acontece lo pedagógico, donde se relacionan los sujetos y sus saberes. El aula integral se monta en diferentes escenarios: salones de clase, barrios, plazas, fábricas, instituciones varias, desplazándose a la vida cotidiana de quienes la integran. Además, transgrede el tiempo y asume una temporalidad más amplia, posibilitando traspasar los límites de los tiempos curriculares y respetar los de los actores y las actoras con quienes trabajamos.

En este sentido, es importante que los EFI puedan sostenerse en proyectos o programas de extensión mayor. Contar con este sostén a modo de plataforma permite acumular experiencias, tomar tiempo para conocerse, generar lazos de confianza. Construir procesos de demanda y problemas de intervención que emerjan de las necesidades e intereses identificados colectivamente. Así, no se limita la presencia de la universidad a la edición de un EFI que supone un tiempo curricular semestral o anual de marzo a noviembre y que luego se va. Contar con proyectos y programas que trabajen con los sujetos todo el año durante varios años, creando y recreando nuevas propuestas, supone un punto de partida de relación constante, respetuosa y más adecuada. Convierte a las personas en habitantes de una territorialidad que se construye de manera compartida.

En tanto, desde esta potencia, identificamos una perspectiva de extensión que va más allá de proyectos de corto plazo, orientados por fondos concursables. Se apuesta a procesos de larga duración en los cuales tanto universitarios y universitarias como quienes no lo son, o no participan de los EFI desde esa referencia, son necesarios para poder llevar adelante propuestas de extensión e integrales de largo aliento. Que acumulen, que aborden nuevas problemáticas, que construyan diversos saberes y conocimientos y que permitan que se desarrollen diferentes propuestas de formación en ese marco.

La segunda potencia que encontramos en los dispositivos EFI es la "capacidad de crear imágenes-pensamiento" (Cavalli, 2019). Como decíamos, los EFI pueden crear escenas diversas en distintos contextos, y los y las integrantes del EFI son protagonistas de esas escenas. Se trata de crear, capturar imágenes para ver y verse, pero también modos de ver $y$ de verse en colectivo, para pensar juntos y juntas y compartir. Nuevamente, se trata de 
la creación de nuevos enunciados y visibilidades, de nuevos saberes. Generar una nueva imagen del aula universitaria que nos muestra otros sujetos, otros modos de relación y de producción. También es una imagen distinta acerca del pensar como un acto racional y metódico; es pensar desde la relación, el afecto y deseo.

Hablamos de la imagen en su uso como estrategia didáctica; usar imágenes para pensar a partir de ellas. Pero también hacemos referencia a la posibilidad de imaginarnos, de crear otras imágenes y por ello pensar de otro modo. Por otra parte, implica romper con la idea de que hay una imagen-pensamiento (un modo de pensar) posible, o una imagen más válida que otras. De esta manera se da lugar a la diversidad de imágenes, pensamientos y saberes que pueden convivir unos con otros.

Por esto decimos que los EFI tienen la potencia de crear imágenes y pensamientos construidos desde el diálogo de saberes, desde modos distintos de estar y ser, dando visibilidad a experiencias que existen y que emergen cotidianamente. Así se ve y se piensan una ciencia distinta, una enseñanza distinta y una universidad distinta.

\section{Métodos, técnicas y estrategias didácticas para estar y producir en colectivo}

Pensar en diálogo de saberes es pensar en conversación, en múltiples miradas que se encuentran y producen colectivamente. Para ello es necesario generar instancias para encontrarse y conversar, dar tiempo a pensar y dar vueltas en torno a algo, cambiar la mirada, cambiarse. También, para que esto suceda, hay de desearlo y hay que proponérselo. Desde nuestra experiencia identificamos algunos abordajes, métodos, técnicas y herramientas didácticas que podemos utilizar para promover el diálogo y la participación. Esto no quiere decir que los en EFI o las herramientas que aquí compartimos generen el diálogo de hecho o impidan desacuerdos. Las herramientas disponen, promueven un espacio de escucha, de tiempo para conversar, argumentar, para evidenciar diferentes puntos de vista que están presentes. En ocasiones, en los equipos de trabajo se esconden jerarquías, relaciones de opresión y desigualdad. Muchas de estas son naturalizadas producto del sistema en el que vivimos. Lo que proponemos es que cada equipo se dé la posibilidad de utilizar y crear herramientas para tramitar estos conflictos; seguramente, de otra forma no habrá diálogos horizontales y condiciones de igualdad entre sujetos y saberes.

En primer lugar, nos encontramos con la propia interdisciplina (componente de la integralidad) como un abordaje fundamental y una apuesta necesaria de los equipos universitarios para generar prácticas de extensión e integrales. En segundo lugar, hallamos en la etnografía una perspectiva para producir desde la experiencia que además nos ofrece algunas técnicas y claves particulares para producir propuestas colaborativas (Rappaport, 2007). Por último, presentamos algunas estrategias didácticas que apuestan a la participación y a la generación de conversaciones.

\section{Hacia la conformación de un equipo: el abordaje interdisciplinario}

"Cada disciplina, cada campo, cada decisión epistemológica provoca este juego de apertura $y$ de clausura y eso forma parte 
de nuestros límites. No hay solo un intercambio de lugares entre las metáforas, sino también un intercambio de lugar de intérpretes $y$ a veces hay aspectos de pelea y de huida". (Ardoino, 2005)

Conformar un equipo y una práctica interdisciplinarios no es tarea sencilla. Como plantea Rolando García (2011), la interdisciplina implica partir de un marco epistemológico y un lenguaje común. Para ello es necesario enmarcarse en un proceso que muchas veces inicia con miradas desencontradas pero con el interés de pensarse y producirse como equipo universitario para trabajar colectivamente. En este sentido, decimos que la interdisciplina no está dada de hecho por la participación de universitarios que provengan de diferentes disciplinas, sino que la misma se da en el devenir de la experiencia del grupo, en el que se irán construyendo ese punto de vista y lenguaje compartido.

Los equipos se van encontrando con diferentes léxicos y formas de expresión, con distintas perspectivas y modos de pensar el conocimiento y el saber, así como de abordar los problemas sociales. Muchas veces esto requiere un "proceso de traducción" (Sousa Santos, 2006) para construir un lenguaje con el cual se entiendan y puedan comunicarse al interior del equipo, así como un lenguaje para expresar y compartir sus ideas y propuestas a otros y otras.

En definitiva, lo que se pone en juego son los diferentes modos de saber y relacionarse con el saber, por lo que supone un proceso de identificar la diversidad y las diferencias y crear un nuevo modo que sea común. Esto no quiere decir que se oculte o se niegue la especificidad de cada disciplina, sino que ese nuevo modo sea construido desde la propia diversidad, contemplando las diferencias. Es necesario romper con el supuesto de que cada disciplina posee una propiedad sobre un determinado campo de conocimiento de manera que excluya a otra. Implica construir una mirada compleja sobre la realidad y los problemas que se abordan, porque la realidad es in-disciplinada.

Pero, como decíamos, la interdisciplina se gesta en el proceso, en la experiencia, no está previamente dada. Por lo tanto, es a la vez un desafío para los equipos, requiere de espacios de escucha, de reflexividad y aprendizaje. Es por esto que pensamos que el abordaje interdisciplinario es un primer paso hacia el diálogo de saberes, ya que implica la construcción con otros y otras que vienen de experiencias distintas dentro de la universidad.

\title{
La etnografía como método para conocer-se
}

\author{
"Monta tu película a medida \\ que la filmas. En ella se forman \\ núcleos de fuerza y seguridad \\ a los que se aferra todo el \\ resto". (Bresson, 2016, p. 20) \\ "Atrapar un instante. \\ Espontaneidad, frescura". \\ (Bresson, 2016, p. 19)
}


Pensamos que la etnografía se conforma como un método para conocer-se, para estar con otros y otras. Es por ello que esta perspectiva y algunas de sus herramientas nos resultan acertadas a la hora de pensar prácticas de extensión e integrales, en las cuales se llevan adelante procesos en los que también se investiga y se produce conocimiento. Asimismo, los aspectos éticos, de análisis y de rigurosidad son de gran aporte para pensar el lugar de los sujetos en la experiencia que supone la formación integral. Nos permite recuperar experiencias al interrogar las propias teorías desde la práctica (Fasano, 2019).

De esta manera se convierte también en una herramienta para enseñar y para aprender desde la escucha y el reconocimiento de los sujetos y sus saberes. Aprender ante la presencia de un otro-otra que se nos presenta como desconocido, ajeno, diferente. Por otra parte, las técnicas de observación participante y las entrevistas en profundidad nos ofrecen estrategias que promueven el diálogo y el encuentro.

Estas claves etnográficas aportan a las prácticas integrales aspectos metodológicos que consideramos fundamentales para los procesos de extensión que nos propongamos hacer. Igualmente, en tanto se trata de estrategias flexibles, nos permiten acompañar la vida, de modo que a partir de ellas podemos generar conocimiento colectivo. Se trata de coproducir o, como plantea Rappaport (2007), de producir en colaboración.

Muchas veces escuchamos o solemos decir que las prácticas de extensión e integrales suceden en el "campo". Pero a qué nos referimos con "campo". Desde la etnografía podemos entender al campo como aquel espacio, porción de la realidad, que queremos conocer, repleto de interacciones entre actores y actoras. Es el espacio donde acontecen las experiencias. El campo se construye entre sujetos que lo conforman, no es cerrado ni está fuera, sino que es una construcción de la que también somos parte (Gandarias, 2014). Nos acompañan en ese campo o en esa construcción del campo las ideas, las lecturas, las teorías que tenemos. Pensamos en una idea de "campo-tema" (Spink, 2005) como aquel lugar en el que nos posicionamos, un espacio de relaciones, ideas, palabras, pensamientos. Como plantea Rebellato (2015), se trata de nuestra práctica como universitarios y universitarias, ligada a un compromiso social y político a partir del cual podemos reconocer y reivindicar otros saberes y producir conocimiento de manera colectiva. Por eso, en extensión, el trabajo de campo no es una parte del trabajo sino que es "el" trabajo.

Como planteamos, la etnografía nos aporta algunas técnicas que son de gran utilidad para embarcarnos en nuestro trabajo de campo. Identificamos tres de ellas que creemos sirven para llevar adelante cualquier práctica extensionista.

En principio, podemos decir que la técnica por excelencia de la etnografía - y a mi entender de la extensión- es la observación participante. La misma implica una serie de actividades variadas que se acuerdan con quienes vamos a trabajar. Supone observar "todo aquello que acontece en torno" (Guber, 2004, p. 115) a quien observa. También nos instala en el proceso de estar y ser juntos y juntas, intentando generar instancias de "corresidencia" (Guber, 2004), de compartir la mayor cantidad de actividades y tiempo posibles. Creemos que producir instancias de observación participante y de corresidencia posibilita crear un contexto disruptivo de la enseñanza universitaria tradicional que conlleva una reconfiguración de la escena pedagógica hegemónica y su imagen. Son escenas, aulas, instancias pedagógicas que cambian, que se mueven, que se transforman y en la que "no hay roles estereotipados de educador y educando, donde todos y todas pueden aprender y enseñar" (UdelaR, 2010). 
Otra de las técnicas de gran utilidad son las entrevistas abiertas. Como plantea Guber (2004), se trata técnicas orientadas por la conversación que permiten el surgimiento de temáticas diversas, de modo de dar significado a aquello que observamos e incorporar temas que quizás no hayan sido previstos. Aconsejamos que sean realizadas luego de algunas instancias de observación participante para que nos otorguen algunas pistas de por dónde ir durante las entrevistas. Pensamos que ambas técnicas pueden usarse conjuntamente para dar profundidad y riqueza a los procesos de extensión con diálogo de saberes en los que se busca coproducir.

El registro es otra herramienta de gran valor para los EFI y para cualquier práctica integral. Como decíamos, se observa todo y también se registra todo. Se registran personas, acciones, tiempo, espacio (Guber, 2004) y también pensamientos, reflexiones, afectaciones, dudas, preguntas que nos van surgiendo. Registramos lo que pasa y lo que nos pasa. Aunque debemos saber que la vida cotidiana no puede ser completamente capturada en nuestro registro. Tanto los modos de registrar como los momentos para registrar son variados. Podemos, por ejemplo, utilizar diario o cuaderno de campo, grabar, sacar fotografías, videos, dibujar, podemos registrar durante la activad que observamos o después. La elección del tipo de registro va a depender de las actividades en las que vamos a trabajar, los temas, las preferencias de los y las participantes, por lo que se deberá decidir conjuntamente teniendo en cuenta qué es lo más adecuado en función de lo que queremos registrar y de cómo queremos hacerlo. Además, debemos prestar atención a los efectos del registro, ya que incide -como nuestra presencia - en la dinámica de lo real. Esto no quiere decir tratar de que no afecte, sino integrar los efectos al análisis, al proceso de producción.

Consideramos fundamental el hecho de registrar porque nos permite generar un proceso transversal de aprendizaje y análisis de las actividades de extensión, así como reorientarlas y reorganizarlas. Se trata de un ida y vuelta entre la teoría y la práctica, un proceso de praxis. De la mano con esta idea, y en tanto la etnografía requiere una centralidad en la experiencia, tomamos la noción de "reflexividad" (Cruces, 2003; Gandarias, 2014; Guber, 2004; Svampa, 2008), también aportada por la etnografía.

Decimos que la experiencia es "eso que me pasa" (Larrosa, 2009), eso que me pasa con otros y otras, ante la presencia de otro, otra, de algo exterior a mí. Es algo que me pasa, que me afecta, que tiene que ver conmigo. Pasa en mí, soy el territorio de la experiencia, en donde va a quedar "una huella, una marca, un rastro, una herida". Pero igualmente es algo desconocido, conlleva cierta incertidumbre, no sabemos todo lo que nos puede pasar. También la experiencia es singular, única e irrepetible.

Las prácticas integrales como espacios de relaciones, de acontecimientos y produccciones, están repletas de experiencias. Ello requiere un constante ejercicio de "reflexividad" de las mismas, en ese sentido, sobre nosotros y nosotras, sobre nuestros cuerpos en la experiencia colectiva, en el encuentro, en ese espacio de afectaciones. Poner a jugar lo que sentimos, lo que pensamos, lo que nos pasa con. Porque estamos en la experiencia, no podemos quedarnos afuera, establecer una distancia, ocultarnos. O, como plantea Ibáñez (2001), "no podemos ver la realidad desde fuera de la realidad para saber cómo sería esta si no estuviéramos en ella" (p. 34). Estamos en la realidad, en esa realidad que construimos, problematizamos, pensamos, creamos, solo a partir de nuestra presencia.

La etnografía supone un registro ético y de análisis transversal al que nos integrarnos como sujetos de la experiencia, incorporando nuestros sentidos y afectos a la hora de pro- 
blematizar y analizar. Integrar para reconocer y descentrarse, para alejarse y ver más allá; desde ahí producir conocimiento, a partir de la experiencia. Reflexionar y pensar sobre prácticas integrales es reflexionar sobre el saber, sobre el encuentro, sobre la vida con otros y otras; es en ese vivir que se despliegan prácticas portadoras de saberes. A este respecto, la reflexividad nos permite pensar lo que hacemos y cómo lo hacemos, aportar a reconstruir las relaciones de poder de manera de cocrear y evitar posiciones extractivistas o contemplativas. Implica también reflexionar sobre las desigualdades de poder existentes en los espacios en los que trabajamos (Gandarias, 2014). Por eso pensamos que esta herramienta debe transversalizar nuestras prácticas, para poder visibilizar cómo estamos (juntos y juntas) en las mismas.

Para finalizar este apartado resulta fundamental decir que tanto las técnicas presentadas como la propuesta de ejercicio de reflexividad son herramientas que todas y todos los participantes del EFI pueden llevar adelante. Cuando hablamos de extensión y de prácticas integrales como procesos de coproducción situamos a todas y a todos como sujetos de conocimiento. Esto quiere decir que su experiencia es fuente del conocimiento que colectivamente se produce. Asimismo, creemos que esto potencia a los EFI como espacios de formación en los que los sujetos realizan conjuntamente una diversidad de actividades mediante las que aprenden, enseñan, transmiten, producen y difunden conocimientos y saberes.

\section{Estrategias didácticas participativas}

Consideramos que en los EFI los abordajes presentados son a la vez contenido teórico y metodológico, así como estrategias para aprender y enseñar, ya que en dichos espacios aprendemos haciendo. Pero además podemos ir incluyendo otras estrategias y dinámicas que apuesten a la participación. Apostamos a la creatividad y espontaneidad que la integralidad requiere y promueve, encontrándonos con una gran variedad de herramientas para ello. Lo que queremos es generar intercambios, discusiones, integración. En este sentido, más que presentar una dinámica específica, lo que podemos compartir son algunos recursos que a utilizar en las diferentes propuestas que realicemos.

En primer lugar, aparece la pregunta como recurso estratégico para favorecer la participación. Las preguntas atraviesan los encuentros cuando se trabajan contenidos específicos. Podemos preguntar qué pensamos sobre algo, qué entendemos sobre tal palabra o concepto, qué otras experiencias similares hemos tenido. $Y$ también orienta los procesos de problematización, por ejemplo, pudiendo llevar algunas preguntas al encuentro con otros y otras o elaborándolas para generar trabajos finales e informes. Nos posiciona en un escenario de posibilidad que abre a lo desconocido y lo nuevo.

La utilización de recursos visuales y audiovisuales es otra de las estrategias que podemos integrar a una multiplicidad de propuestas. Partir de imágenes, fotos, videos o películas para conversar, preguntar, generar espacios de intercambio, y para introducir contenidos teóricos, voces y experiencias. Por otro lado, puede convertirse en una estrategia para registrar, porque, como decíamos, el registro no solo puede ser escrito. Vemos que el uso de cámaras, grabadoras, incluso del dibujo, muchas veces resulta más accesible a la hora de registrar lo que acontece. También podemos utilizar estrategias de construcción de escenas o juegos de roles como forma de imaginar, poner en acción y colectivizar nuestras percepciones, intereses, emociones, afectos sobre un tema, un problema o sobre el proceso mismo que vamos 
a llevar adelante o que estamos haciendo Además, a través de producciones visuales y audiovisuales podemos compartir y difundir las prácticas que realizamos y los conocimientos a los que arribamos en el proceso de las mismas. Muchas veces así aportamos lenguajes, modos de decir y contar más accesibles y dinámicos.

Como decíamos, ambos recursos pueden integrarse a diferentes actividades y propuestas para facilitar la participación y el intercambio, y nos permiten recuperar e integrar preconceptos, expectativas, experiencias y saberes que, aunque no los evidenciemos, se pondrán en juego en los encuentros, por lo que asimismo podemos favorecer instancias de reflexividad y pensamiento colectivas.

\section{Los EFI: un aula de saberes en movimiento}

El diálogo de saberes como proceso de co-construcción requiere tiempo, acumular, demorarse en este objetivo que nos orienta. No podemos forzarlo, no hay una receta para que se cumpla. Nos lleva a disponernos para otra temporalidad, una temporalidad demorada, ocupada en encontrase, en conocerse, en generar confianza, lazos afectivos. Se necesita tiempo para conversar, para estar juntos y juntas. Aprender de los tiempos de los otros y de las otras, sin apuros. Por eso no es posible anteponer el diálogo de saberes al devenir de sí mismo. Lo que sí se comienza a coproducir es la propia práctica educativa. Como decíamos, el EFI, en tanto dispositivo, está integrado por saberes y relaciones con el saber y entre los sujetos, y es en el marco del mismo que se conforma la práctica educativa integral.

En este sentido, los y las integrantes del EFI lo construyen planteando intereses, necesidad actividades, días, horarios, estrategias para llevar adelante acciones, etc. Del mismo modo, a partir de pedidos, ofertas y necesidades (Rodríguez, et al., 2015), se co-construyen los problemas que se propone abordar. Es en estas acciones y prácticas cotidianas que se despliegan los saberes que se van a poner en relación y a dialogar. Así se construye colectivamente un aula, un escenario pedagógico, como construyen los modos de estar en el EFI, de habitarlo.

Esta perspectiva nos lleva a repensar la propia noción de diálogo de saberes. La integralidad es una propuesta flexible, creativa; ello no quiere decir que no sea rigurosa, sino que es capaz de adaptarse a las múltiples escenas de la vida. De igual forma, una noción de diálogo de saberes desde esta perspectiva tampoco puede estar previamente estructurada. Lo que queremos decir es que si esperamos encontrarnos solamente con unos saberes objetivados, que puedan ser capturados o identificados, probablemente no seamos capaces de verlos, de ver la riqueza que en nuestras prácticas desplegamos y ponemos en diálogo y relación. Por eso decimos que el diálogo de saberes es meta y guía de la integralidad. Es el deseo de encontrarse y producir juntos y juntas lo que orienta nuestras prácticas.

En síntesis, decimos que en los EFI se presentan nuevos "modos de pensar y de hacer" e insisten en "la preocupación por la vida colectiva" (Teles, 2009, p. 28). Estar y ser juntos y juntas requieren de la conformación de espacios de producción colectivos. Lo colectivo invita a pensar y a construir. Los EFI se conforman como dispositivos que permiten y promueven "instalar un escenario de encuentro, un aula itinerante, una práctica en movimiento y un territorio pedagógico común" (Cavalli, 2019). Se trata de propuestas sostenidas desde el deseo, desde un modo deseante, en el que la enseñanza se vuelve "un acto político y ético" (Tommasino, et al., 2017). 
Los equipos docentes que llevan adelante los EFI deben mantener una posición consecuente entre teoría y práctica, entre sus concepciones y herramientas didácticas, y compartir su posición epistemológica, teórica, ética y metodológica, haciéndola presente en tanto contenido pedagógico. De esta manera también construyen estrategias para compartir y discutir acerca de estos contendidos, desde el diálogo, desde la apuesta a la existencia de otros y otras en la práctica educativa, posicionando a quienes integran los EFI como co-contructores de la misma.

La integralidad nos sitúa frente una transformación epistemológica acerca de la enseñanza universitaria. No solo se requieren reformas y resoluciones sino nuevos modos de hacer enseñanza, de hacer ciencia, de estar juntos y juntas, en definitiva, de hacer realidad, de hacer mundo. Nos posiciona en tensión, ante una imagen de la academia que nos incomoda y nos mantiene inconformes. Es por ello que nos proponemos mostrar otras imágenes y otros pensamientos, que son múltiples, que están en movimiento, que no se dejan capturar, pero que existen. La creación de EFI nos da la posibilidad de visibilizar una academia que enriquezca nuestra vida. Así como también crear prácticas en donde quienes no participan de los EFI como universitarios o universitarias integren la universidad de forma activa, construyéndola. "Pensamos que esta es la imagen real de una universidad pública, de una democratización del conocimiento, en donde los sujetos no institucionalizados también son parte y también pueden ser sujetos productores de conocimiento" (Cavalli, 2019).

Por último, queremos expresar que, si bien la integralidad se ha institucionalizado en la UdelaR, sigue requiriendo movimientos instituyentes (Kaplún, 2014). Aunque sabemos que hay una gran riqueza de prácticas con estas características, aún están instalados otra imagen y otros discursos sobre la universidad y la enseñanza universitaria, por ello resulta fundamental no solo realizar sino registrar, sistematizar y compartir estas prácticas.

\section{Referencias bibliográficas}

Ardoino, J. (2005). Complejidad y formación: Pensar la educación desde una mirada epistemológica. Novedades Educativas.

Bresson, R. (2016). Notas sobre el cinematógrafo. La orgía de las polillas.

Cano, A. \& Castro, D. (2013). Análisis de los modelos pedagógicos en las prácticas educativas universitarias que integran la extensión a la formación curricular. (Investigación). IPES.

Cavalli, V. (2019). Imágenes de un aula en movimiento. Pensamientos sobre los saberes en la enseñanza universitaria integral. (Tesis de Maestría). UdelaR.

Charlot, B. (2000). El saber y las figuras del aprender. En La relación con el saber. Elementos para una teoría. (pp. 67-86). Trilce.

(2008). La relación con el saber, formación de maestros y profesores, educación y globalización. Trilce. Cruces, F. (2003). Etnografías sin final feliz. Sobre las condiciones de posibilidad del trabajo de campo urbano en contextos globalizados. Disparidades. Revista de Antropología, 58(2), 161-178.

CSEAM. (2015). Formulación de proyectos de extensión universitaria. Extensión.

Deleuze, G. (2007). ¿Qué es un dispositivo? En Dos regímenes de locos. Textos y entrevistas (1975-1995) (pp. 305-312). Pretextos.

Fasano, P. (2019). Tras la vitalidad de lo social. El uso de la etnografía en los procesos de extensión universitaria, una estrategia para la integralidad de funciones. +E: Revista de Extensión Universitaria, 10(10), 3-16. 
https://doi.org/10.14409/extension.v9i10.Ene-Jun.8286

Fernández, A. M. (2007). Las lógicas colectivas. Biblos.

Foucault, M. (2011). Historia de la sexualidad. Vol. 2: El uso de los placeres. Siglo XXI Editores. (2013). La arqueología del saber. Siglo XXI Editores.

Gandarias, I. (2014). Habitar las incomodidades en investigaciones feministas y activistas desde una práctica reflexiva. Athenea Digital, 14.

García, F. (2011). ¿Qué es un dispositivo?: Foucault, Deleuze, Agamben. A Parte Rei. Revista de filosofía, 74.

García, R. (2011). Interdisciplinariedad y sistemas complejos. Revista latinoamericana de Metodologías de las Ciencias Sociales, 1, 67-1001.

Guattari, F. (1996). Las tres ecologías. Pretextos.

Guattari, F. \& Rolnik, S. (2006). Micropolítica. Cartografías del deseo. Traficantes de sueños.

Guber, R. (2004). El salvaje metropolitano: Reconstrucción del conocimiento social en el trabajo de campo. Paidós.

Ibáñez, T. (2001). Fondear en la objetividad o navegar hacia el placer? Athenea Digital: Revista de Pensamiento e Investigacion Social, 31-37.

Kachinovsky, A. \& Gatti, E. (2005). Entre el deseo de enseñar y el placer de aprender. Psicolibros.

Kaplún, G. (2014). La integralidad como movimiento instituyente en la universidad. InterCambios. Dilemas y transiciones de la Educación Superior, 1(1), 44-51.

Larrosa, J. (2009). Experiencia y alteridad en educación (Presentación). En Experiencia y alteridad en educación. $1^{\text {ra. }}$ edición. Homo Sapiens.

Nygren, A. (1999). Local knowledge in the environment-development discourse: From dichotomies to situated knowledges. Critique of anthropology, 19(3), 267-288.

Percia, M. (2010). Inconformidad arte política psicoanálisis. La Cebra.

Puiggrós, A. (2013). El lugar del saber. Galerna.

Puiggrós, A. \& Gagliano, R. (2004). La fábrica del conocimiento. Los saberes socialmente productivos en América Latina. Homo Sapiens.

Rappaport, J. (2007). Más allá de la escritura: La epistemología de la etnografía en colaboración. Revista colombiana de antropología, 43, 197-229.

Rebellato, J. L. (2015). La contradicción en el trabajo de campo. En Formulación de proyectos de extensión universitaria (pp. 67-81). Extensión universitaria.

Rodríguez, A.; Giménez, L.; Netto, C.; Bagnato, M. J. y Marotta, C. (2015). De ofertas y demandas: Una propuesta de intervención en Psicología Comunitaria. En Formulación de proyectos de extensión universitaria (pp. 67-81). Extensión universitaria.

Skliar, C. (s.f.). Como estar juntos en las instituciones educativas. https://www.youtube.com/watch?v=5rPEZhEObzl

Skliar, C. (2010). Los sentidos implicados en el estar-juntos de la educación. Revista educación y pedagogía, $56,101-111$.

Sousa Santos, B. de (2006). Renovar la teoría crítica y reinventar la emancipación social. Clacso.

- (2010). La universidad del siglo XXI. Para una reforma democrática y emancipatoria de la universidad. Trilce.

Spink, P. (2005). Replanteando la investigación de campo: Relatos y lugares. Athenea Digital. Revista de pensamiento e investigación social, 1(8).

Svampa, M. (2008). Notas provisorias sobre la sociología, el saber académico y el compromiso intelectual. En Gérard Althabe, Entre varios mundos. Prometeo. 
Teles, A. L. (2009). Política afectiva. Apuntes para pensar la vida comunitaria. Fundación la Hendija.

Tommasino, N.; Viñar, M.; Cavalli, V. y Cardozo, D. (2017). Acompañar y sostener el deseo. Coproducción de conocimiento en la integralidad: Aportes pedagógicos, (2), 53-66. https://psico.edu.uy/sites/default/files/2017-07/coproduccion-de-conocimiento-final-web.pdf

UdelaR (2010). La extensión en la transformación de la enseñanza: Los Espacios de Formación Integral. (Vol. 10). UdelaR. 